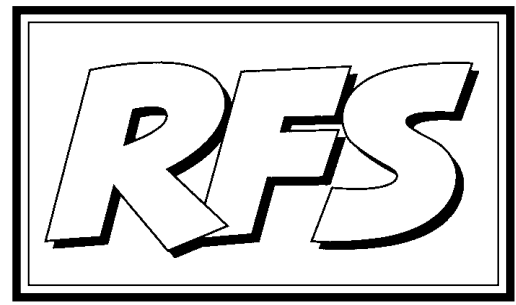

Revista de Fomento Social, 54 (1999), 261-270

\title{
Miedo del trabajador y derecho social
}

En este ensayo en cierto modo provocador, el autor ilustra la evolución del derecho del trabajo siguiendo el hilo conductor de los «miedos» de los trabajadores a lo largo de las últimas décadas de la historia de España. En el mismo se afirma la actual tendencia del derecho del trabajo consiste en pasar de ser un instrumento de protección del trabajador y del débil a un derecho administrativo de empresa. El autor parte del convencimiento de que el derecho laboral, por sí mismo, ni crea ni destruye empleo. Y sin embargo hoy parece que se le exige al derecho del trabajo resultados económicos, sobre todo la creación y promoción de empleo. Precisamente en una obra dirigida por el autor («dialéctica empleo-desempleo y derecho social»), que recensionamos en nuestra Revista no hace mucho (n ${ }^{\circ} 212$, octubre-diciembre 1998, p. 587 ss.), se reflexiona con mayor extensión y profundidad sobre esta cuestión.

(*) Profesor de ESADE. Universidad Ramón Llull. Barcelona. 


\section{Una introducción histórica común}

Si se me permite remendar a Juan en su Evangelio, yo me atrevería a iniciar el tema que nos ocupa, «miedo del trabajador y derecho social», diciendo que «al principio era el proletariado, y el proletariado estaba en el miedo, y el proletariado era el miedo. Esto era al principio».

Es decir, el miedo del trabajador y el derecho social han ido juntos en la historia. Puede, incluso, que hayan nacido juntos. Porque tenía miedo el trabajador, es decir, miedo ante la amenaza de la pobreza, necesidad subjetivamente resentida de protección, nació el derecho social de manos del Estado.

Y junto al miedo, al principio también fue la cólera. Una cólera (colectiva) con la que nació un derecho social (colectivo) que quitase el miedo al trabajador. Es decir, cólera y miedo en el mundo del trabajo fueron siempre juntos al comienzo gracias a la mediación del derecho social (estatal y colectivo). De un derecho social que se crea por el Estado para proteger al trabajador del miedo, y que, al mismo tiempo, es creado por la cólera de los trabajadores para protegerse del miedo (si no también del Estado). De ahí la doble estructura originaria del derecho social. Una más estatal, destinada a crear garantías individuales en favor del trabajador contra el miedo congénito, y otra más colectiva que diera cauce y salida a la cólera y con ella protegiese a los trabajadores del miedo.

\section{La primera tradición española}

Esa doble tradición, de intervención estatal y de cólera obrera, que nacieron juntas para hacer desaparecer el miedo, también se ha dado en España, como país afectado, aunque sea con un calendario más retrasado, por la dinámica social (miedo) de la sociedad industrial. La dimensión de la cólera obrera se expresó en la gran doble tradición sindical española, la socialista (de color marxista, la UGT) y la anarquista (de color bakunista, la CNT). La comunista, y por paradójico que pueda parecer a algunos, es una tradición reciente, que sólo llega a expresarse en el franquismo, si es que no nació con él realmente (CCOO).

Pero la tradición histórica dominante como protección contra el miedo, ha sido la estatal. Lo que ha predominado, como instrumento de superación del miedo, ha sido la parte asumida por el derecho delEstado y por las instituciones delEstado, destinados ambos a construir y fortalecer en las relaciones laborales un vínculo 
social distinto del civil y dominado por la protección. En esto, es decir en términos de intervención, España se parecería más a Francia que a otros países. En Francia seguramente esa intervención va unida y ha ido históricamente unida a una idea y a una tradición administrativas de racionalidad. En España, lo que seguramente ha dominado no es tanto la racionalidad, cuanto la necesidad resentida socialmente de sentirse protegidos por elEstado. Cuando se habla de un Estado «Providencia» moderno, puede que en España éste no esté tan desarrollado como en otros países europeos, pero en cambio sí si se puede decir que aquí la Providencia siempre ha sido pensada en términos de Estado, el garante más fuerte del derecho social.

En efecto, una vez concluidas, a imitación de Europa o juntamente con Europa, las primeras leyes sociales protectoras (por ejemplo, las leyes de 1873, 1878 y 1900, de protección del trabajo de los niños y las mujeres, del tiempo del trabajo, del trabajador accidentado, del aprendiz...), el sistema que nace (y que se hace adulto con la dictadura de Primo de Rivera), es un sistema más bien corporativo/estatalista. En él, las reglas de protección del derecho social se crean mediante comités mixtos que actúan bajo la autoridad y garantía del Estado y con su iniciativa y protección. Los socialistas (marxistas) cooperan en este sistema. Largo Caballero, militante socialista del PSOE (Partido Socialista Obrero Español) y de la UGT, condenado a muchos años de prisión por una huelga, y, luego, Ministro de Trabajo en el primer gobierno de la segunda República, fue miembro del Consejo de Estado en la Dictadura de Primo de Rivera.

Con la llegada de la segunda República este sistema no cambia esencialmente. Los cambios del sistema de relaciones de trabajo son casi sólo terminológicos (los comités mixtos o paritarios se llamarán jurados mixtos). Y si es verdad que, junto a los jurados mixtos, se proclama la negociación colectiva en la Ley de contrato de trabajo de 1931, también es verdad que no cambió con ello gran cosa la realidad por diferentes motivos. Incluido el del miedo al desorden político. En el mismo año 1931, la Ley de defensa de la República castigaba con pena de cárcel el no respeto del preavisoen ciertos casos dehuelga. Ciertamente, se confiaba másen laintervención del Estado que en la cólera obrera. De hecho, y por paradójico que pueda parecer, la sociedad española sólo aprendió a negociar con el franquismo. La sociedad de la República era una sociedad rural, primitiva, bipolarmente dividida, y dominada por el miedo, cuya última expresión fue la guerra civil, que ideológicamente perdió el movimiento obrero en aras de un todopoderoso «Estado Nuevo». 


\section{La tradición franquista}

Con el franquismo esta línea estatalizadora dominante se exacerbó al máximo. La exacerbación fue doble. Primero, política, y auto-legitimada con la exaltación de la protección individual de un trabajador que siempre había vivido en el miedo (lo que justificaba eliminar la autoprotección sindical clásica, la de la clase obrera y las libertades obreras). Si el Estado (interventor) era social, ya no era necesaria la cólera obrera, ni las libertades creadas por la cólera obrera (libertad sindical, huelga, negociación colectiva).

En segundo lugar y en términos jurídicos, esa protección del trabajador individual se articuló en todos los planos de fácil intervención del Estado. Por ejemplo, en el tema del despido. Con el franquismo, el despido individual era de práctica muy difícil. El despido individual por motivos económicos no existía, y el colectivo exigía la autorización de la Administración de Trabajo. Sí existía, en cambio, el despido disciplinario, pero su práctica no era fácil, con la lógica excepción de que lo que se jugara en ello fuese una razón política. En ese caso, a la Magistratura de Trabajo, una creación del proteccionismo franquista que vaciaría de contenido cualquier ensayo de Tribunal mixto, no le quedaba otro remedio que aplicar la ley aceptando el despido. Pero si no se trataba de motivos políticos, la Magistratura recuperaba su vocación natural de protectora del trabajador, interpretando la ley con principios similares a los penales del «in dubio, pro reo» (aquí, pro operario), que parecían hechos a medida de esa protección intencionada del trabajador (bueno).

Más allá de sus funciones primarias de control y vigilancia, a la Administración se le asignaban funciones decisivas de autorización (empresarial) muy amplia, y no sólo en los despidos colectivos. La Administración intervenía prácticamente en todas las decisiones de la empresa, en los que se jugasen intereses de los trabajadores. Y cuando con la liberación económica, las condiciones del trabajo se fijen por convenios colectivos, éstos deberán ser homologados por la Administración para ser jurídicamente válidos. Fue tan intervencionista el sistema, que la inspección de trabajo, además de cumplir con sus funciones naturales, asumió en los hechos el papel del fomento del diálogo social. Los inspectores de trabajo fueron los pedagogos del diálogo social con respecto a trabajadores, empresarios, y hasta a jueces .

Finalmente, convendría señalar otros dos puntos de este intervencionismo 
estatal, muy expresivos de la protección individual de los trabajadores entonces dominante. Por un lado, los sindicatos oficiales gestionaban la protección cotidiana de los trabajadores gratuitamente, gracias a un cuerpo de letrados sindicales que hoy los sindicatos desearían imitar en su nuevo modelo de «sindicatos de servicios». Y por otro, no habría que olvidar que la Seguridad Social llegó a su grado máximo de protección social con el franquismo. Seguramente hubiera llegadocon cualquier otro régimen político, dadas las condiciones económicas de la Europa de entonces. Pero es verdad que de hecho fue con el franquismo cómo el sistema de seguros sociales dispersos se convirtió en un sistema de seguridad social. Como también es verdad que los trabajadores experimentaron las primeras dificultades y recortes del sistema con el postfranquismo.

Naturalmente, en este sistema de protección del trabajador era la protección del trabajador individual la que contaba. La protección colectiva que no fuera de la Administración, las libertades colectivas, eran nulas, o sólo existían para elCódigo Penal. Los sindicatos fueron disueltos y sustituidos por el corporativismo sindical (del nacionalsindicalismo que definía al régimen en teoría). Y la huelga, prohibida como un delito de «lesa patria», volvió al Código Penal. La negociación colectiva fue suprimida. Y cuandoésta, por razones económicas, se recupere de algún modo a finales de los 50, lo que se buscará con la ley (al margen de lo que termine resultando en los hechos) será una colaboración de los agentes sociales con la Administración para fijar las condiciones de trabajo, algo más cercano y parecido a los comités y jurados mixtos de la Dictadura de Primo de Rivera y de la República que a la negociación colectiva de la Europa de la segunda postguerra.

De todos modos, lo que sí es verdad es que cuando España se abra en el tardofranquismo a la modernidad económica, también se dará una apertura política en forma de tolerancia, y hasta de cierta aceptación de las libertades colectivas del trabajo (sindicalismo más o menos clandestino, ciertos tipos de huelga) frente al Estado que sigue pretendiendo mantener su responsabilidad social como monopolio natural suyo. Y que ese cambio, hecho mitad de tolerancia y mitad de aceptación cómplice, se da sin disminución alguna del sistema de protección individual existente. Una debilitación de esa protección hubiese sido socialmente interpretada como un ataque directo al mundo obrero, al que se había querido sacar del miedo con el apoyo del Estado. 


\section{Los cambios políticos del postfranquismo}

Tuvo que venir la transición para que cambiase el sistema. Y para que, con este cambio, se aceptara socialmente una disminución de la protección individual del trabajo. Es decir, con la transición, con el desconcierto de lo nuevo, con las necesidades apremiantes de una búsqueda de lo político, que además de necesaria fue absorbente (obsesiva hasta descuidar las soluciones económicas a las dificultades económicas de los 70, que el franquismo había disimulado por razones políticas), se dibuja un sistema nuevo (D.L de 4 de marzo de 1977) que ofrece claramente una menor protección individual (por primera vez, se inscribe en el derecho el despido individual no disciplinario, y nada menos que en cuatro modalidades diferentes), como precio que hay que pagar por las libertades sociales colectivas, al tiempo que, congruentemente con ello, se anuncia también una menor intervención administrativa.

Con la Constitución y el Estatuto de los Trabajadores se consolida ese proyecto. Tanto que el autor material del Estatuto ha podido decir que con el Estatuto se instala en el derecho toda la protección social colectiva (que no se tenía), pero se vaciaba al derecho de todas las garantías de protección social individual (que se tenían, como nunca se habían tenido).

Cambios de este tipo nunca son socialmente fáciles. Pero lo son aún menos si van acompañados, como en el caso español, de un proceso de desvelamiento de una crisis económica que se había intentado camuflar anteriormente, y cuya expresión más aguda fue el desempleo.

A la muerte de Franco la tasa de desempleo en España era del 1,91\% de la población activa (265.000 desempleados). Cuando se plantea la gran reforma del 94, esa misma tasa es del 23,9\% y los desempleados son 3.700.000.

Cada etapa de gobierno marcó un aumento del paro. El gobierno que dictó el citado D.L de 4 de marzo del 77 aumentó en 250.000 el número de parados, que así llegaron a la cifra de 507.000. El primer gobierno salido de las primeras elecciones (el que promovió el primer intento de negociación de partidos y sindicatos con las Pactos de la Moncloa) dejó, al dimitir el ministro de economía, en febrero del 78, 237.000 parados más, quedando el número de éstos establecido en 744.000.

Con los dos años y medio de Abril Martorell como ministro de economía (cuarto gobierno de Suárez, gobierno en el que tuvieron lugar acuerdos interconfederales 
muy importantes y la propia ley delET) la cifra de parados se dobla, llegando a ser de 1.315.000. Cifra que en el siguiente gobierno de Calvo Sotelo, y con García Añoveros de ministro de economía, aumenta en unos 400.000, hasta llegar a ser los parados 1.744.000. Cifra ésta última, que con un nuevo ministro sube aún más, unos 200.000 más, hasta llegar a 1.967.000 los desempleados que hereda el primer gobierno socialista a finales de 1982.

Los socialistas habían predicado la cruzada del empleo, hasta prometer 800.000 empleos nuevos, no se suponunca muy bien si anuales o por legislatura. La realidad fue otra. El primer ministro socialista (Boyer), al marcharse en julio de 1985, dejó 2.893.000 desempleados (unos 925.000 más que antes). El segundo ministro socialista (Solchaga) añadió unos 655.000 más (hasta dejar unos 3.546 .000 desempleados, al abandonar el ministerio en julio de 1993). Y el tercer ministro (Solves) ya tenía en el primer trimestre de 1994, el año de la primera gran reforma del derecho social español, unos 152.000 parados más. En ese momento el número de desempleados era el indicado más arriba: unos 3.700.000, el 23,9\% de la población activa. El desempleo era ahora la plaga social. Y lo era como resultado de una política (primariamente socialista, por paradójico que parezca) de modernización económica. Más económica que social desde luego.

\section{La situación actual}

¿Qué significaron socialmente los cambios del postfranquismo? Piensoque para entenderlo había que distinguir tres colectivos sociales: 1) el movimiento obrero; 2) los sindicatos; y 3) los trabajadores.

1) Para el movimiento obrero, el postfranquismo significaba la libertad, la democracia y el bienestar social. Y la percepción obrera (una especie de presumptio iuris) era la de que esos tres elementos positivos irían juntos, unidos. Las libertades colectivas no eran concebiles sin democracia. Y unas y otras no lo eran sin bienestar social garantizado.

2) Para los sindicatos (en cuanto distintos del movimiento obrero) el postfranquismo significó también tres cosas: a) por un lado, el tiempo de recomponerse fuera de la clandestinidad; b) por otro, la cólera, la nueva cólera libremente expresada al servicio de un derecho que protegiera a los trabajadores. Peroc) también significó, y pronto, la aparición de sus intereses corporativos. Apenas salidos de la oscuridad de la clandestinidad, los 
sindicatos empezaron a preguntarse cómo ser «sindicatos más representativos», y cómo serlo sólo ellos, es decir, cómo ser sujetos de poder político.

3) Finalmente, para los trabajadores, el postfranquismo significó muy pronto: a) una constatación jurídica, que habría más libertad (negociación colectiva y huelga) pero menos protección (un despido casi libre); b) una constatación económica, las insuficiencias económicas traerían insuficiencias de protección jurídica. Con los socialistas en el poder, una huelga general e inútil de los sindicatos (hermanos de aquéllos) contra la primera reforma de la Seguridad Social (denominada «racionalización» es decir, reducción «de las pensiones») les enseñaría que en adelante contaría la economía más que la justicia. Que ésta era una cosa de dinero. Y c) que se iniciaba la crisis del estado de bienestar cuando aún no se había tenido tiempo de saber que lo teníamos. Y que, en adelante, el dato más relevante y cotidiano sería el desempleo. Un desempleo que abría de nuevo las puertas del miedo a un trabajador desprotegido.

\section{Las reformas del 94 y del 97}

De hecho, la reforma del 94 fue presentada como una operación de normalización y saneamiento sociales, y ello en un doble sentido. Primero, había que desplazar el derecho estatal en beneficio de la autonomía colectiva que-pensaban los gobiernos socialistas de turno- defendería mejor los intereses sociales en una sociedad democrática libre. Segundo, había que flexibilizarel mercado de trabajo, desregularlo, desreglamentarlo, para hacer posible la creación de empleo. De las dos caras del derecho social, el derecho al empleo y el derecho en el empleo, se sacrificó la segunda a la primera. Pero la verdad es que nadie sabe si ese sacrificio sirvió para algo. De hecho, el empleo no acudió a la cita, y lo que sucedió fue la entronización en el derecho del trabajo del interés de empresa como si se tratase de un interés común.

Pero no se trataba de un interés común, sino de la vuelta a la prehistoria del derecho del trabajo nacido del miedo y de la cólera, al derecho civil primero que había entronizado el interés del empresario. Paradójicamente, este interés de empresa así rebautizado romperá todas las veces que haga falta la lógica contractual civil, pero ahora no en favor del trabajador, sino en favor del empresario, apenas disimulado en el interés de empresa, terminología que bautizaba a las razones 
económicas técnicas, organizativas y de producción de siempre.

Y ello tanto en la vida del día a día del trabajo (movilidad funcional, movilidad geográfica, cambios sustanciales de las condiciones de trabajo...), como en el fin de la vida del trabajo (despido económico, que, mientras no rebase ciertas magnitudes de envergadura, quedará a merced de la libertad del empresario, contra la vieja tradición española de la intervención administrativa), como en el propio delineamiento de las medidas de políticas de empleo, cada vez más reducidas a reglas de flexibilización (junto a bonificaciones) por si surge el milagro.

Pero, entre tanto, la filosofía implícita en el derecho del trabajo ha cambiado. Y ese cambio ha sido socialmente aceptado. La reforma del 97 confirma la del 94. Antes de esas reformas, al menos formalmente, el principio que hizo nacer (del Estado o de la cólera) el derecho del trabajo, separaba claramente al trabajador del riesgo del empresario. Clásicamente, éste era del empresario y sólo del empresario. Si ganaba mucho, tanto mejor para él. Si le iban mal las cosas, ése era su problema.

En España la reforma del 94 (junto a otras cosas positivas, probablemente: mayores espacios de diálogo social que luego suprimió en buena parte la reforma del 97) introdujo en el derecho, sin utilizar el nombre, el concepto de riesgo compartido. En adelante, si las cosas van mal para el empresario, también irán mal para el trabajador que tendrá que sacrificar su empleo (o sus condiciones de trabajo) en aras del interés (económico) superior del empresario. Y si le van bien, eso, para el trabajador, sólo querrá decir que no perderá su empleo, que seguirá donde y como estaba.

\section{Conclusión}

Una concepción como ésta de riesgo compartido (para el mal) entre empresario y trabajador implica una concepción nueva del derecho del trabajo. Nueva y vieja. Porque es la vuelta al miedo. Porque no hay que dejar de recordar, por obvioque resulte, queel derecho social actual ha hecho de la precariedad del trabajo y de las condiciones de trabajo, su característica predominante. Como tampoco habría que olvidar, aunque sea igualmente obvio, que esa precariedad social va unida a una riqueza creciente, que hace aún mayor la distancia entre unos (muy ricos) y otros (los afectados de esa nueva enfermedad que habría que llamar «minusvalía social») en una sociedad en mutación, que hoy segrega como 
subproducto suyo a los marginados, al modo como el siglo XIX segregó a los proletarios.

Ha vuelto el miedo. ¿Y la cólera? Simbólicamente, todavía pacíficamente, en algunos países (Francia, por ejemplo), los parados ya han dado signos de impaciencia sacando la cólera a la calle, es decir a hoteles y restaurantes de lujo. ¿Y si esa ola se extiende? ¿Y si ese fuego prende incontroladamente? Por miedo, o por decencia, valdría la pena reflexionar sobre ello y poner los remedios para evitarlo. Sobre todo, si todo proviene de algo que hemos hecho, sin saber muy bien lo que hacíamos. Sólo forzados por acontecimientos que no dominábamos. O esperando el milagro. ¿Y si no existen los milagros? 